\title{
Ultrasonographic Determination of Portal Vein Diameter Among Adults with and without Chronic Liver Disease at Selected Referral Hospitals in Southern Ethiopia
}

Tsegazeab Ayele (D)

Abinet Gebremickael (iD)'

Mathewos Alemu Gebremichael (iD) ${ }^{2}$

Mala George ${ }^{3}$

Habtamu Wondmagegn (iD)

Habtamu Esubalew ${ }^{2}$

Zekarias Bukala'

Simeon Meskele (D)

Getachew Abebe (iD)

Alehegn Bekele'

'Department of Anatomy, College of Medicine and Health Sciences, Arba Minch University, Arba Minch, Ethiopia; ${ }^{2}$ Department of Public Health, College of Medicine and Health Sciences, Arba Minch University, Arba Minch, Ethiopia; ${ }^{3}$ Department of Biochemistry, College of Medicine and Health Sciences, Arba Minch University, Arba Minch, Ethiopia
Background: Measuring portal vein diameter (PVD) is a feasible method of detecting portal vein hypertension, which is a primary and fatal complication of chronic liver disease (CLD) and is usually diagnosed very late. However, there is a paucity of morphometric information on portal vein diameter in the Ethiopian population. Hence, it is important to determine the portal vein diameter among adults with and without chronic liver disease.

Purpose: The study aimed to identify how PVD is affected by age, sex, and anthropometric measurements in patients with and without CLD.

Methods: A cross-sectional study was conducted among 220 participants (110 CLD patients and 110 controls) who have visited the radiology unit at selected Hospitals. Patients with CLD were selected consecutively as they present while controls were selected by a systematic sampling technique. A structured questionnaire was used to collect the data. Correlation and independent $t$-test were used to assess the relations. A statistically significant association was declared at P-value $<0.05$.

Results: Mean portal vein diameter for CLD patients was $17.03 \pm 1.97 \mathrm{~mm}$ with a range of $12.8-20.8 \mathrm{~mm}$ and $10.79 \pm 1.27 \mathrm{~mm}$ with a range of $7.70-13.25 \mathrm{~mm}$ for the control group. Age, weight, and body mass index had a positive correlation with portal vein diameter in both groups. The mean portal vein diameter increased by $21.34 \%$ during deep inspiration in the control group.

Conclusion: The mean portal vein diameter among patients with CLD was higher than that of the control group. A significant gender-based difference was recorded in the portal vein diameter of the control group only. Ultrasonography is a non-invasive, readily available diagnostic tool for portal vein pathology.

Recommendation: It is recommended for clinicians to take into consideration age, sex and anthropometric measurements while measuring PVD.

Keywords: portal vein diameter, portal hypertension, chronic liver disease, Ethiopia

\section{Introduction}

Portal vein (PV) is the main channel of the portal venous system and clinically important structure as it is usually associated with portal hypertension (PHT). PHT is the elevation of the hepatic venous pressure gradient (HVPG) to $>5 \mathrm{mmHg}$, which is the primary complication of chronic liver disease (CLD). ${ }^{1,2}$ The prevalence of cirrhosis has increased by five times between 1990 and 2017 and more than
Correspondence: Habtamu Wondmagegn P.O. Box No: 21, Arba Minch, Ethiopia Tel +251913028959

Fax $+25 \mid 468810279$

Email habtamuwondmagegn@gmail.com; habtamu.wondmagegn@amu.edu.et 
1.32 million deaths due to cirrhosis have been recorded, which is $2.4 \%$ of the total death by $2017 .^{3}$ This substantial number of death is to some extent accounted for the late diagnosis of CLD. Thereby patients may present with upper gastrointestinal bleeding associated with a $20-30 \%$ mortality rate with each episode of bleeding and a $60-80 \%$ chance of re-bleeding within a year after the first episode. ${ }^{4,5}$ Meanwhile, the clinical diagnosis of liver cirrhosis and PHT is seldom established until complications such as bleeding from oesophageal varices have become apparent. However, studies demonstrate that in only onethird of patients with PHT the collaterals will use the oesophageal pathway and thus alert the clinicians to the elevated pressure in the portal system while the remaining two-third of collateral do not bleed apparently. ${ }^{6}$

Hence, portal vein assessment should be widely practiced for screening, diagnosis, and follow-up of PHT since it is the primary complication of chronic liver disease. Because of its use of non-ionizing radiation, easy accessibility, non-invasive nature, portability, low cost, and ability to rapid accomplishment, sonography is claimed as a good diagnostic tool for patients with portal hypertension. ${ }^{7}$ Besides, Sonography of the liver is often the first examination performed in a patient with clinical and laboratory signs of liver disease. However, inconsistent findings of sonographic measurements of PVD were reported even within a nation. For example, a study conducted by Hawaz et al at Tikur Anbesa Specialized Hospital, Addis Ababa, Ethiopia reports that there is no gender-based difference in the PVD of the normal population, ${ }^{8}$ on the other hand study conducted in Jimma, stated significantly wider PVD male than female. ${ }^{9}$

Moreover, in sub-Saharan Africa, there is a paucity of information regarding the relationship between different anthropometric parameters and PVD. In addition, there is no study conducted to determine the relationship between PVD and anthropometric variables in CLD patients. Surprisingly, a reference point used to detect PHT so far in Ethiopia is a value set for the population of foreign countries.

All these facts imply the need for studies for building advanced knowledge on the morphometric anatomy of PVD by comparing individuals with and without CLD on basis of PVD affecting factors. This helps in enhancing the capacity of health professionals in diagnosing and monitoring follow-up of patients with PHT. Such information is essential and studies of this kind have not been conducted in Ethiopia. Therefore, this study intended to determine portal vein diameter among adults with and without chronic liver disease at selected referral hospitals in southern Ethiopia.

\section{Methods and Materials}

Study Area and period: The study was conducted at Wolaita Sodo university teaching and referral hospital (WSUTRH) and Nigist Ellene Mohamed Memorial Referral Hospital (NEMMRH) located in Southern Ethiopia, from December 2020 to July 2021.

Study Design: Cross-sectional study design was implemented.

Study Participants: The study population consists of two groups; adult CLD patients and patients without CLD (controls) who visited the radiology unit for sonographic evaluation reasons other than hepatobiliary disease.

\section{Inclusion Criteria}

Age 18 years or above and who had not had a meal for at least six hours was the inclusion criteria for patients without CLD. Patients without hepato-biliary disease has no hepatobiliary surgery, or recent surgery for other reasons, age of 18 or above, and who had fasted for at least six hours were included in the control group.

\section{Exclusion Criteria}

Pregnant women were excluded from the study group of patients with CLD. While participants who are pregnant, consume alcohol, are taking hepatotoxic drugs, have cardiac disease, and have any ultra-sonographic evidence of liver diseases were excluded from the control group.

\section{Sample Size Determination and Sampling Procedure}

Sample size was calculated based on PVD for age relationship by using Fisher's z test comparing two independent correlations with assumptions of Pearson's correlation coefficient (r), the significance level (a), and the power. ${ }^{10}$ Pearson's correlation coefficient of 0.681 for controls and 0.242 for patients with CLD was taken from the previous study in Nigeria by Usman et al 2015. ${ }^{11}$ And power 80 and significant level of 0.05 were assumed (Table 1).

Since the sampling procedure was two steps, to adjust the design effect, multiplying 50 by two, the sample size was 100 for each group. Then, Adding $10 \%$ of the nonresponse rate on 100 the total sample size became 110 for each group. The sample size was proportionally allocated. 
Table I Sample Size Determination for the Study Population

\begin{tabular}{|l|c|c|c|c|c|}
\hline Study Group & Pearson's Correlation Coefficient & Significant Level & Power & Ratio & Sample Size \\
\hline Control & 0.681 & 0.05 & 80 & 1 & 50 \\
Patients with CLD & 0.242 & 0.05 & 80 & 1 & 50 \\
\hline Total & & & & 100 \\
\hline
\end{tabular}

Then, patients with CLD were selected consecutively as they present while controls were selected by a systematic sampling technique.

\section{Data Collection}

A structured pretested interviewer-administered questionnaire consisting of three sections: socio-demographic (age and sex), anthropometric measurements (height, weight, and BMI), and parameters for PVD was used. The weight and height of the patients were measured using standardized height and weight measurements for adults. The weight and height were read to the nearest $0.1 \mathrm{~kg}$ and $0.1 \mathrm{~cm}$ by using beam balance (QF-2003A, China) and tap meter (Kaida, China), respectively. The weight of ascitic patients was adjusted by subtracting 2.2, 6, and $14 \mathrm{~kg}$ from the actually measured weight of grade one, grade two, and grade three ascitic patients, respectively. ${ }^{12}$ To check the instrumental consistency 5 normal subjects were tested using (EDAN U2 prime edition, China) and (SONOSCAPE SSI-8000, China) ultrasound machines. Then, the precision of the machines was tested by calculation the Cronbach alpha value, which was found to be 0.981 .

\section{Measurements}

The participants were in the supine position. Then before measuring PVD, the hepatobiliary system was scanned by the radiology residents, and patients diagnosed with CLD were included in patients with the CLD study group, and any signs of hepatobiliary disease were excluded from the control study group. The diameter of the portal vein was measured from the inner-to-inner wall of the echogenic wall in longitudinal and transverse cross-section just before the bifurcation at the widest part of the blood vessel (Figure 1).

An average of three times measurement was taken to minimize measurement error. The measurement was done with deep inspiration, expiratory, and a quiet respiratory phase using a $3.5 \mathrm{MHz}$ curvilinear probes of EDAN U2 prime edition and SONOSCAPE SSI-8000 ultrasound machines. Then, a respiratory phasic variation of PVD was calculated as follows: mean deep inspiratory minus deep expiratory and divided by mean deep inspiratory PVD multiplied by 100 .

\section{Data Processing and Statistical Analysis}

Data were entered into Epi Data version 3.1 and exported to SPSS version 25 for management and analysis. The characteristics of the study population were described using descriptive statistics like means, standard deviations, frequencies, and proportions. The normality assumption was checked by the Shapiro-Wilk test and it was normal (P-value $=0.083$ and 0.279$)$ for patients with CLD and controls, respectively. The linearity (between independent and dependent variables) was checked by using a scattered plot and the relation was linear. The third assumption: homocedesity of the dependent was checked and the variance was homogenous. Then, the relation between PVD with age, weight height, and BMI was determined by Pearson's correlation coefficient. An Independent $t$-test was used to compare portal vein diameter between patients with CLD and controls, as well as the difference between sexes. A P-value of less than 0.05 was considered statistically significant for the correlation and independent $t$-test.

\section{Results}

\section{Sociodemographic and Clinical Characteristics of the Study Participants}

220 study participants participated in the study with a response rate of $100 \%$. Half of the study participants (110) were either patient with CLD or controls. The majority of patients with CLD were males (70.9\%). While among controls, the females (53.6\%) were slightly more than males. We reported no difference in mean age $(\mathrm{P}=0.068)$ and height $(\mathrm{P}=0.261)$ between patients with CLD and controls. However, there was a significant difference in weight $(\mathrm{P} \leq 0.001)$, BMI $(\mathrm{P} \leq 0.001)$, PVD $(\mathrm{p} \leq 0.001)$, and respiratory phasic variation of $\mathrm{PVD}$ 


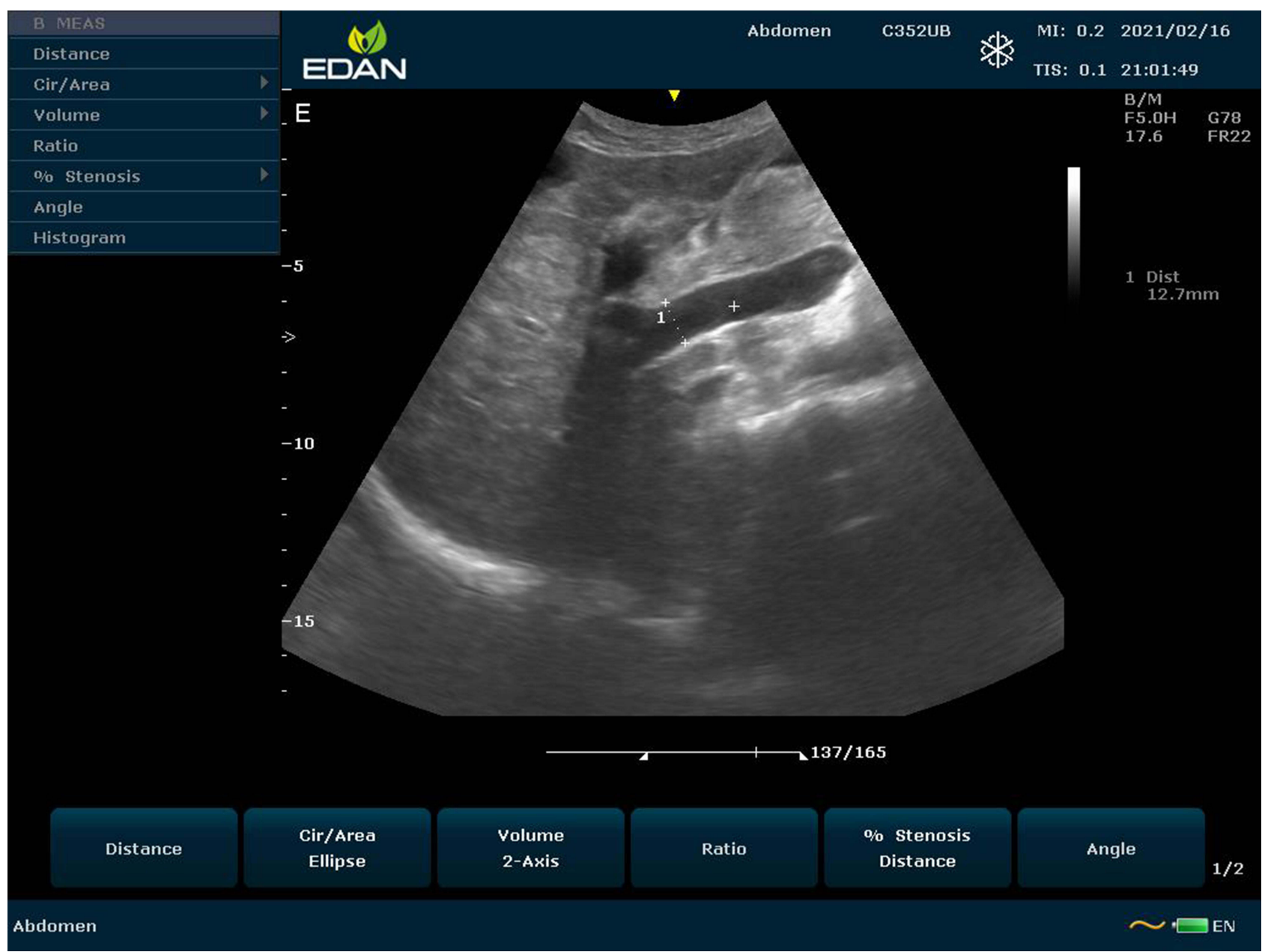

Figure I Ultrasonography image showing the level of measurement of the main portal vein and echogenic wall of lumen on a longitudinal section.

$(\mathrm{p} \leq 0.001)$ between patients with $\mathrm{CLD}$ and controls. Almost all CLD patients have presented with ascites (107) 97.3\% and Grade 3 ascites accounted for (58) $54.2 \%$ followed by Grade 2 ascites (44) $41.1 \%$. Similarly, all patients had splenomegaly which is confirmed by ultrasound (Table 2).

\section{Respiratory Phasic Portal Vein Diameter Variation of Patients with CLD and Controls}

The mean portal vein diameter increased by $8.92 \%$ during deep inspiration in patients with CLD. While the respiratory phasic variation of the PVD control group increased by $21.34 \%$. However, we reported no difference in Respiratory phasic variation of PVD between males and females in both patients with and without CLD (Table 3).

\section{Determination of Portal Vein Diameter in Patients with CLD and Control Group}

Although the mean PVD of patients with CLD, was larger in males $(17.18 \pm 1.83)$ than females $(16.68 \pm 2.28)$ it was insignificant $(\mathrm{P}=0.23)$. However, the mean $\mathrm{PVD}$ difference between males $(11.1 \pm 1.21)$ and females $(10.53 \pm 1.27 \mathrm{~mm})$ was significant $(\mathrm{P}=0.017)$ in controls, which shows the anatomical size difference between males and females (Table 4).

A small linear relationship exists between age and means PVD among patients with CLD $(r=0.224$, $\mathrm{P}=0.018$ ) reported that relation is more in male patients. While, a strong linear relationship was noted between mean PVD in controls and age $(r=0.259, \mathrm{P}=0.048)$ by which the relation is more in female patients. Indicating PVD increases as age increase (Table 4).

The correlation between the mean PVD of patients with CLD with anthropometric parameters was small in both sexes' 
Table 2 Sociodemographic and Clinical Characteristics of Patients with CLD and Controls at Selected Referral Hospitals Southern Ethiopia, 2021

\begin{tabular}{|c|c|c|c|c|}
\hline \multicolumn{2}{|l|}{ Variables } & \multirow{2}{*}{$\begin{array}{l}\text { Patients with CLD ( } \mathrm{n}=\mathrm{I} \text { I } 0) \\
(78) 70.9 \%\end{array}$} & \multirow{2}{*}{$\begin{array}{l}\text { Controls }(n=I I 0) \\
(5 I) 46.4 \%\end{array}$} & \multirow[t]{3}{*}{ P-value } \\
\hline Sex & Male (n)\% & & & \\
\hline & Female $(n) \%$ & (32)29.1\% & $(59) 53.6 \%$ & \\
\hline \multicolumn{2}{|l|}{ Age (mean $\pm S D$ years) } & $41.33 \pm 11.25$ & $38.52 \pm 11.43$ & 0.068 \\
\hline \multicolumn{2}{|l|}{ Weight (mean \pm SD kg) } & $48.76 \pm 6.96$ & $60.36 \pm 7.01$ & $0.00 I^{*}$ \\
\hline \multicolumn{2}{|l|}{ Height (mean $\pm \mathrm{SD} \mathrm{cm}$ ) } & $164.85 \pm 4.76$ & $163.95 \pm 6.8$ & 0.261 \\
\hline \multicolumn{2}{|l|}{$\mathrm{BMI}\left(\right.$ mean $\left.\pm \mathrm{SD} \mathrm{kg} / \mathrm{m}^{2}\right)$} & $17.96 \pm 2.62$ & $22.50 \pm 2.55$ & $0.001 *$ \\
\hline \multicolumn{2}{|l|}{ PVD (mean \pm SD mm) } & $17.03 \pm 1.97$ & $10.79 \pm 1.27$ & $0.001 *$ \\
\hline \multicolumn{2}{|l|}{ PVD (range mm) } & $12.8-20.8$ & $7.70-13.25$ & \\
\hline \multicolumn{2}{|c|}{ Respiratory phasic PVD difference (mean $\pm S D$ ) } & $8.92 \%$ & $21.34 \%$ & $0.00 I^{*}$ \\
\hline \multirow[t]{2}{*}{ Portal hypertension indicators } & Ascites $(n) \%$ & 107 (97.3\%) & - & - \\
\hline & Splenomegaly (n)\% & $110(100 \%)$ & - & - \\
\hline
\end{tabular}

Note: *P-value $<0.05$

categories with a significant relationship $(\mathrm{P}<0.05)$ in weight and BMI, but with height. While there was a moderately strong and significant relation between the mean PVD of controls and weight $(\mathrm{r}=0.309, \mathrm{P}=0.001)$ which shows the larger the bodyweight the wider PVD (Table 4).

\section{Discussion}

Portal hypertension can be caused by any condition that interferes with blood flow at any level within the portal system and the causes are usually subcategorized as prehepatic, intrahepatic, and post hepatic. Intrahepatic causes account for over $95 \%$ of cases of portal hypertension and are represented by the major forms of cirrhosis. ${ }^{4}$ A study conducted in southern India among adults has also reported $90 \%$ of PHT is caused by CLD. ${ }^{1}$ Similarly, intrahepatic cause of PHT accounts for most cases in the pediatric age group $93 \% .^{2}$

In the present study, 220 patients with or without CLD were investigated in this cross-sectional study. The purpose of our study was to sonographically assess the relationship between portal vein diameter and age, sex, and anthropometric variables among patients with CLD and controls. The mean PVD in the current study is comparable with previous standards. The main findings also established that there is the sex difference in PVD among controls and varies with age, height, weight, and
BMI. While, there was no sex difference in PVD and does not vary with height, among patients with CLD.

The mean normal portal vein diameter was found to be $10.79 \pm 1.27 \mathrm{~mm}$ which is in line with studies conducted elsewhere. ${ }^{9,13-15}$ In a contrary, a study conducted in NorthEastern India by Saha et al 2015, reported a lower mean normal PVD $(8.83 \pm 2.12 \mathrm{~mm})$, which could be due to the inclusion of participants under 18 years. ${ }^{16}$ Similarly, lower mean PVD $(9.60 \pm 1.41 \mathrm{~mm})$ with relatively lower mean age (32.5 \pm 11.3 years) was reported in a study by Luntsi et al in Northern Nigeria. ${ }^{7}$ Furthermore, we reported a significant $(\mathrm{P}=0.017)$ difference in the mean PVD between males $(11.1 \pm 1.21 \mathrm{~mm})$ and females $(10.53 \pm 1.27 \mathrm{~mm})$ in the control group. Similarly, a study done in Ethiopia, ${ }^{9} \mathrm{Nepal}^{15}$ and India ${ }^{16}$ reported that the PVD is significantly larger in males than females. The similarity could be due to the average liver size in males being larger than the female. However, previous studies by Adeyenkun and Tsebi, ${ }^{17}$ Gareeballah et $\mathrm{al}^{13}$ and Hawaz et $\mathrm{al}^{8}$ do not report the statistically significant differences in PVD between males and females. A positive correlation between normal PVD and age within males $(\mathrm{r}=0.224, \mathrm{P}=0.114)$ and females $(r=0.294, r=0.002)$ was noted in the current study. This supports the increasing PVD with age observed by most studies. ${ }^{8,9,11,15}$ The positive correlation could be due to the effect of growth. Although, Study by Saha et al reported 


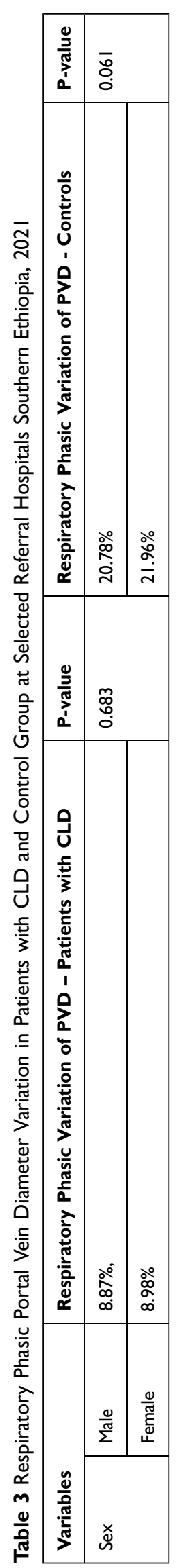

no association $(\mathrm{r}=0.015, \mathrm{P}=0.880)$ between $\mathrm{PVD}$ and age. $^{16}$

The mean PVD in CLD patients in the current study was much larger $(17.03 \pm 1.97 \mathrm{~mm})$ than that of the normal participants $(10.79 \pm 1.27 \mathrm{~mm})$. This could be because the raised pressure in the portal venue's system dilates the blood vessels in the system to accommodate the pressure. Our finding was supported by studies conducted in Nigeria $^{11}$ and Italy. ${ }^{18}$ The variation in measurement of PVD in CLD patients in other studies could be due to early or late-stage disease during the time study since the change in diameter of the vein is minimal in its early stage (due to lower pressure) and late-stage (due to formation of collateral anastomosis) of the disease. Besides, our finding indicated the statistically non-significant difference in PVD of males and females in patients with CLD and agrees with a study in Nigeria. ${ }^{11}$ Moreover, the present study showed a moderately strong and significant positive correlation between PVD and age within male CLD patients $(\mathrm{r}=0.328, \mathrm{P}=0.003)$. In contrary, a study by Usman et al in North-Eastern Nigeria, reported a negative correlation between PVD and age within male CLD patients $(\mathrm{r}=-0.273, \mathrm{P}=0.00) .{ }^{11}$ However, we did not find a statistically significant correlation between PVD and the age of female CLD patients $(\mathrm{r}=0.03, \mathrm{P}=0.89)$ in the present study. A study done in Nigeria reported a negative but not significant correlation $(\mathrm{r}=-0.212, \mathrm{P}=0.153)$ of $\mathrm{PVD}$ and age of female patients with CLD. ${ }^{11}$ The pathologic condition of PVD which may lead to an irregular pattern of change of PVD with disease progression despite participants' age could have contributed to varying findings in the association of age with PVD in different studies.

Anthropometric measurement has been reported to correlate with PVD in normal population. ${ }^{14,19}$ This study report shows the correlation between PVD and weight and BMI of patients with CLD and but not with height. On the other hand, our finding supports medium-strength correlation between weight and PVD among controls in studies conducted elsewhere. ${ }^{13,16}$ Although, there are studies that failed to show a correlation either between height or BMI and PVD among patients without CLD, ${ }^{16}$ our findings support the study by Gareeballah et al in Sudan that reported a positive correlation. ${ }^{13}$ The increment in PVD as the body parameters increase could be due to proportional increment of blood vessels with body size and internal organs.

Clinically, PVD of greater than or equal to $13 \mathrm{~mm}$ is suspected for PHT. Similarly, study by Bolondi et al revealed PVD diameter of $\geq 13$ indicates PHT with $41.8 \%$ 
Table 4 Determinants of Portal Vein Diameter in Patients with CLD and Controls at Selected Referral Hospitals Southern Ethiopia, 2021

\begin{tabular}{|c|c|c|c|c|c|c|}
\hline & \multicolumn{3}{|c|}{ Patients with CLD } & \multicolumn{3}{|c|}{ Controls } \\
\hline & Male & Female & & Male & Female & \\
\hline Mean PVD $\pm S D$ & $17.18 \pm 1.83$ & $16.68 \pm 2.28$ & $P=0.235$ & $11.1 \pm 1.21$ & $10.53 \pm 1.27$ & $P=0.017$ \\
\hline Age (in years) & $\begin{array}{l}r=0.328 * \\
P=0.003\end{array}$ & $\begin{array}{l}r=0.03 \\
P=0.87\end{array}$ & $\begin{array}{l}r=0.224^{*} \\
p=0.018\end{array}$ & $\begin{array}{l}r=0.224 \\
P=0.114\end{array}$ & $\begin{array}{l}\mathrm{r}=0.259 * \\
\mathrm{P}=0.048\end{array}$ & $\begin{array}{l}r=0.294 * \\
P=0.002\end{array}$ \\
\hline Weight (in KG) & $\begin{array}{l}r=0.194 \\
P=0.088\end{array}$ & $\begin{array}{l}r=0.240 \\
P=0.185\end{array}$ & $\begin{array}{l}\mathrm{r}=0.222 * \\
\mathrm{P}=0.02\end{array}$ & $\begin{array}{l}r=0.145 \\
P=0.31\end{array}$ & $\begin{array}{l}\mathrm{r}=0.323^{*} \\
\mathrm{P}=0.013\end{array}$ & $\begin{array}{l}r=0.309 * \\
P=0.001\end{array}$ \\
\hline Height (In Meter) & $\begin{array}{l}r=0.097 \\
P=0.396\end{array}$ & $\begin{array}{l}r=-0.130 \\
P=0.478\end{array}$ & $\begin{array}{l}r=0.079 \\
P=0.41 I\end{array}$ & $\begin{array}{l}r=0.046 \\
P=0.75\end{array}$ & $\begin{array}{l}r=0.147 \\
P=0.267\end{array}$ & $\begin{array}{l}r=0.197 * \\
P=0.04\end{array}$ \\
\hline BMI $\left(K G / m^{2}\right)$ & $\begin{array}{l}r=0.155 \\
P=0.177\end{array}$ & $\begin{array}{l}r=0.297 \\
P=0.099\end{array}$ & $\begin{array}{l}r=0.196 * \\
P=0.04\end{array}$ & $\begin{array}{l}r=0.113 \\
P=0.431\end{array}$ & $\begin{array}{l}r=0.25 \\
P=0.056\end{array}$ & $\begin{array}{l}r=0.197 * \\
P=0.039\end{array}$ \\
\hline
\end{tabular}

Note: *P-value $<0.05$

of sensitivity. ${ }^{18}$ Furthermore, Usman et al demonstrated that the maximum PVD of $13.06 \mathrm{~mm}$ for controls and minimum PVD of $13.14 \mathrm{~mm}$ for patients with CLD by which $13 \mathrm{~mm}$ could be taken as the reference point for PHT detection. ${ }^{11}$ Similarly, in our study, the maximum PVD for the control group was $13.25 \mathrm{~mm}$ and the minimum PVD in CLD patients was $12.8 \mathrm{~mm}$. In the current study, respiratory phasic variation of mean PVD was found to be $21.3 \%$ in the control group. Our finding is in line with Geleto et al and Hawaz et al in Ethiopia. ${ }^{8,9}$ On the other hand, respiratory phasic variation was $(8.92 \%)$ in patients with CLD which is much lower than controls. In patients with CLD, the diameter of the blood vessel is already dilated due to the elevated pressure in the portal venous system and the wall of the blood vessel cannot stretch further to accommodate the change in pressure during inspiration and expiration, unlike a healthy portal vein.

\section{Limitations of Study}

One of the limitations of this study is that, only the diameter of the portal vein was measured and not the portal flow. We did not take into account parameters like patient liver size, which possibly could result in the variation of portal vein study. The study was carried out in patients who visited the hospital for the general health check-up, thus may not be representative of the population.

\section{Conclusion}

To conclude, the mean PVD of patients with CLD in the current study was found to be much larger compared to controls. The PVD difference between males and females was significant in the control group while there was no sex-based difference of PVD in patients with CLD. Portal vein diameter of CLD patients was correlated positively with age, weight, and BMI. Similarly, the PVD of controls is correlated positively with age, weight, and BMI, in addition to height.

\section{Recommendations}

It is recommended that clinicians should take into consideration consider age, sex and anthropometric measurements while measuring PVD as these variables could affect the measurement. Furthermore, researchers are recommended to conduct large-scale study of this kind for identification of precise portal vein diameter in Ethiopian population.

\section{Data Sharing Statement}

The datasets used and analysed in the current study are available from the corresponding author on reasonable request.

\section{Ethical Approval and Informed Consent}

This study was carried out after obtaining ethical approval from Arba Minch University, College of Medicine, and Health Sciences, Institutional Research Ethics Review Board (Ref.no: IRB/555/12; Issue date: 26/11/2020). To ensure confidentiality, it was the anonymous type whereby names of the study subjects were not written on the questionnaire. Written consent 
from the study participants was obtained after they were briefed about the research intent and asked for their willingness to participate in the study. Their right of denial to participate in the study was also assured. This study was conducted per the declaration of Helsinki.

\section{Acknowledgments}

We acknowledge Arba Minch University, study participants, data collectors, supervisors, and Wolaita Sodo University Teaching and Referral Hospital, and Nigist Ellene Mohamed Memorial Referral Hospital for their cooperation.

\section{Author Contributions}

All authors made substantial contributions to conception and design; execution and acquisition of data; analysis and interpretation of data; took part in drafting the manuscript and revising it critically for important intellectual content; agreed to submit to the current journal; gave final approval of the version to be published; and agree to be accountable for all aspects of the work.

\section{Funding}

This research did not receive any specific grant from funding agencies in the public, commercial, or not-forprofit sectors.

\section{Disclosure}

The authors declare no competing interests in this work.

\section{References}

1. Goel A, Madhu K, Zachariah U, et al. A study of aetiology of portal hypertension in adults (including the elderly) at a tertiary centre in southern India. Indian J Med Res. 2013;5(137):922-927.

2. Imanieh MH, Dehghani SM, Khoshkhui M, Malekpour A. Etiology of portal hypertension in children: a single center's experiences. Middle East J Dig Dis. 2012;4(4):206.

3. Sepanlou SG, Safiri S, Bisignano C. The global, regional, and national burden of cirrhosis by cause in 195 countries and territories, 19902017: a systematic analysis for the Global Burden of Disease Study 2017. Lancet Gastroenterol Hepatol. 2020;5(3):245-266. doi:10.1016/ S2468-1253(19)30349-8

International Journal of General Medicine

\section{Publish your work in this journal}

The International Journal of General Medicine is an international, peer-reviewed open-access journal that focuses on general and internal medicine, pathogenesis, epidemiology, diagnosis, monitoring and treatment protocols. The journal is characterized by the rapid reporting of reviews, original research and clinical studies
4. Faucis AS, Kasper DL. Harrison's Principles of Internal Medicine. 17 ed. USA: The McGraw-Hill; 2008.

5. Mendes FD, Suzuki A, Sanderson SO, Lindor KD, Angulo P. Prevalence and indicators of portal hypertension in patients with nonalcoholic fatty liver disease. Clin Gastroenterol Hepatol. 2012;10(9):1033. doi:10.1016/j.cgh.2012.05.008

6. Kurol M, Forsberg L. Ultrasonographic investigation of respiratory influence on diameters of portal vessels in normal subjects. Acta Radiol Diagn. 1986;27(6):675-680. doi:10.1177/ 028418518602700609

7. Luntsi G, Sani M, Zira JD, Ivor NC, Garba SH. Sonographic assessment of the portal vein diameter in apparently healthy adults in a Northern Nigerian population. Afr Health Sci. 2016;16(4):1168.

8. Hawaz Y, Admassie D, Kebede T. Ultrasound assessment of normal portal vein diameter in Ethiopians done at Tikur Anbessa specialized hospital. East Cent Afr J Surg. 2012;17(1):90.

9. Geleto G, Getnet W, Tewelde T. Mean normal portal vein diameter using sonography among clients coming to radiology department of Jimma University Hospital, Southwest Ethiopia. Ethiop J Health Sci. 2016;26(3):237. doi:10.4314/ejhs.v26i3.6

10. Adam M, Baharum N. Sample size guideline for correlation analysis. World J Soc Sci Res. 2016;3(1):9747.

11. Usman AU, Ibinaiye P, Ahidjo A, et al. Ultrasound determination of portal vein diameter in adult patients with chronic liver disease in North-Eastern Nigeria. Sub Saharan Afr J Med. 2015;2(2):57. doi:10.4103/2384-5147.157419

12. Lamarti E, Hickson M. The contribution of ascitic fluid to body weight in patients with liver cirrhosis, and its estimation using girth: a cross-sectional observational study. J Hum Nutr Diet. 2020;33(3):404-413. doi:10.1111/jhn.12721

13. Gareeballah A, Hassan IA, Elzaki M, et al. Measurement of normal portal vein diameter in Sudanese using ultrasonography. Glob $A d v$ Res J Med Med Sci. 2017;6(12):340.

14. Ibinaiye $\mathrm{P}$, Aiyekomogbon $\mathrm{J}$, Tabari M, Chom N, Hamidu A, Yusuf R. Determination of normal portal vein parameters on triplex ultrasound scan among adults in Zaria, Nigeria. Sub Saharan Afr J Med. 2015;2(1):33-38. doi:10.4103/2384-5147.150469

15. Songmen S, Panta Om B, Neupane NP, Ghimire RK. Measurement of portal vein diameter, peak systolic velocity and pulsatility index by ultrasound Doppler evaluation in asymptomatic Nepalese population. J Inst Med. 2017;39(1):42.

16. Saha N, Sarkar R, Singh MM. Portal vein diameter in a tertiary care centre in North-East India. IOSR J Dent Med Sci. 2015;14(12):113.

17. Adeyekun AA, Tsebi HB. Grey-scale sonographic evaluation of portal vein diameter in Nigerian adults. $J$ Biomed Sci. 2014;3(1):24.

18. Bolondi L, Gandolfi L, Arienti V, et al. Ultrasonography in the diagnosis of portal hypertension: diminished response of portal vessels to respiration. Radiology. 1982;142:172. doi:10.1148/ radiology.142.1.7053528

19. Raut RS, Bahetee BH. Study of anatomical dimensions of portal vein. Sch J Appl Med Sci. 2015;3(3):1343. across all disease areas. The manuscript management system is completely online and includes a very quick and fair peer-review system, which is all easy to use. Visit http://www.dovepress.com/ testimonials.php to read real quotes from published authors. 